\title{
Effect of rice husk ash and fly ash on the compressive strength of high performance concrete
}

\author{
Tang Van Lam ${ }^{1,}$, Boris Bulgakov ${ }^{1}$, Olga Aleksandrova ${ }^{1}$, Oksana Larsen ${ }^{1}$, and Pham Ngoc \\ $\mathrm{Anh}^{2}$ \\ ${ }^{1}$ Moscow State University of Civil Engineering, Yaroslavskoe shosse, 26, Moscow, 129337, Russia \\ ${ }^{2}$ Ruhr Universität, Bochum, Bochum, Germany
}

\begin{abstract}
The usage of industrial and agricultural wastes for building materials production plays an important role to improve the environment and economy by preserving nature materials and land resources, reducing land, water and air pollution as well as organizing and storing waste costs. This study mainly focuses on mathematical modeling dependence of the compressive strength of high performance concrete (HPC) at the ages of 3 , 7 and 28 days on the amount of rice husk ash (RHA) and fly ash (FA), which are added to the concrete mixtures by using the Central composite rotatable design. The result of this study provides the second-order regression equation of objective function, the images of the surface expression and the corresponding contours of the objective function of the regression equation, as the optimal points of HPC compressive strength. These objective functions, which are the compressive strength values of HPC at the ages of 3, 7 and 28 days, depend on two input variables as: $\mathrm{x}_{1}$ (amount of RHA) and $\mathrm{x}_{2}$ (amount of FA). The Maple 13 program, solving the second-order regression equation, determines the optimum composition of the concrete mixture for obtaining high performance concrete and calculates the maximum value of the HPC compressive strength at the ages of 28 days. The results containMax ${ }^{28} \mathrm{HPC}=76.716 \mathrm{MPa}$ when RHA $=0.1251$ and FA $=0.3119$ by mass of Portland cement.
\end{abstract}

\section{Introduction}

The concrete experts consider the last two decades of the twentieth century as decades of concrete additives. Thus, the 21 st century will be the century of widespread usage of different types of high-strength concrete and high performance concrete.

The modern technology monolithic construction, used in various countries in the world as well as in Vietnam, widely applied mineral additives in the concrete mixtures. Among these additives, superplasticizers, complex of chemical organic and mineral additives are the most popular [1].

In concrete production technology, the mineral additives are separated to fine active additives and inert additives. Fine active additives helps to reduce cement content and control

\footnotetext{
*Corresponding author: lamvantang@gmail.com
} 
the process of forming concrete structure. While the inert mineral additives in fine grinding has been used so far in order to fill and solidify the concrete structure. In which, the major role is microsilica. It is waste generated in ferroalloy and silicon production. Besides, they are more widely available due to their cheaper price, in spite of slightly less effective than imported micro silica fume. Popular inert mineral additives is fly ash, provided from thermal power plants (FA TPP), metakaolin, fine-grained slag and pumice, especially, reusing waste from brick production, gypsum-containing waste [2].

The human beings use approximately 10 billion tons of minerals and organic materials annually. At the same time, about $10 \%$ to $99 \%$ of these materials are converted into waste, causing soil, water and atmospheres pollution. For example, in coal industry, nearly 1.3 billion tons of overburden, mine rocks and about 80 million tons of wastes of coal enrichment are discharged each year [3].

The rice processing also produces a great quantity of wastes in the form of straw, bran and rice husk. In rice producing countries, one ton of grain is disposed averagely, that is more than one ton of rice straw and husk. Thus, the reuse of these wastes reasonably become high important subject [4].

Rice straw mostly uses for agricultural demand (70\% for cattle food) and construction as finishing and roofing materials (about 5\%). The rest of this is burnt directly in the fields (up to $15 \%$ ) or simply left there, as well as natural decomposition (about $10 \%$ ).

In recent times, main purpose of using rice straw is producing cellulose and its derivatives [5], while rice husk produces silica in crystalline and amorphous forms [6]. Then, amorphous silica is applied in building materials technology. Methods of utilizing agricultural residues in the world are shown in Figure 1.

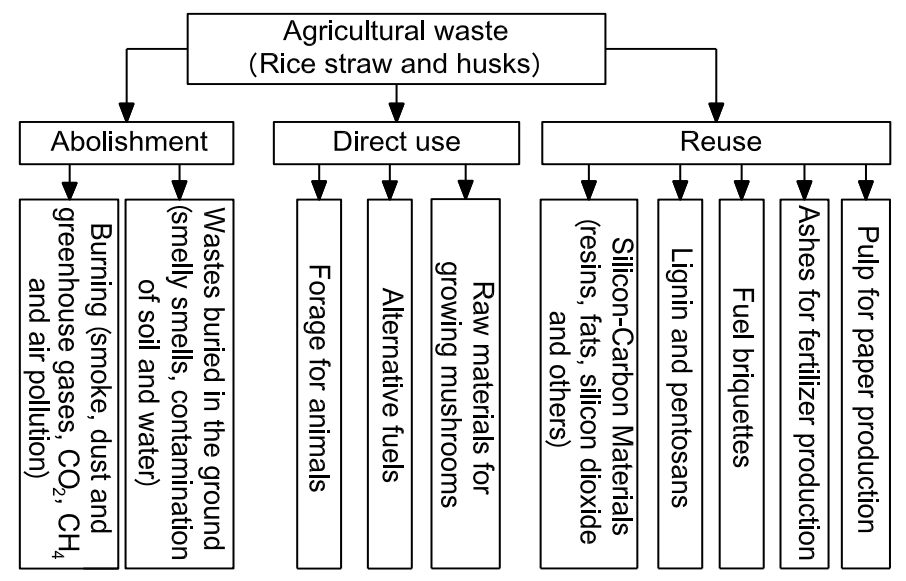

Fig. 1. Methods of disposal of rice straw and husks in the world.

In fact, rice husks have a small bulk density (about $0.1 \mathrm{ton} / \mathrm{m}^{3}$ ) [7], thus its storage requires a large area. Moreover, this storage of waste leads to pollution of soil, water and air [8]. Therefore, processing and recycling of rice husk and straw have a great economic and social importance for the northern regions of the Vietnam, where are concentrated several rice processing companies [9].

In Vietnam, rice straw, a byproduct of rice milling, previously was only used as fuel in small ceramic kilns or for alternative fuels production - rice husk. A small amount of rice husk then was mixed with Portland cement to produce unbaked brick blocks. Presently, the ash is obtained by burning the husk, which consist of huge amorphous silicon content. This ash is widely used in Vietnam as an active mineral additives and replaced imported silica fume in concrete production with different purposes 
The annual amount of industrial waste is more than 150 million tons in Vietnam. In which, metallurgical slag is about $45 \div 55$ million tons, ash and slag TPP is nearly $50 \div 60$ million tons and gypsum wastes is approximately $14 \div 16$ million tons [10].

In 2016, the accumulation of solid wastes from ash and slag, particularly, waste gas and wastewater from the thermal power plant in the industrial zone "VungAng" (Vietnam), have caused seriously environmental pollution in Vietnam central provinces (Figure 2).

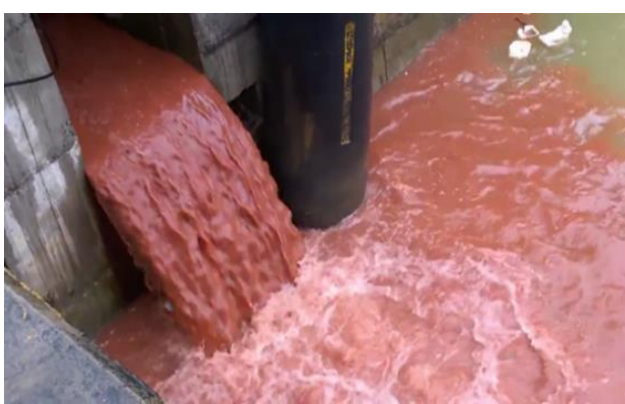

a). Water pollution

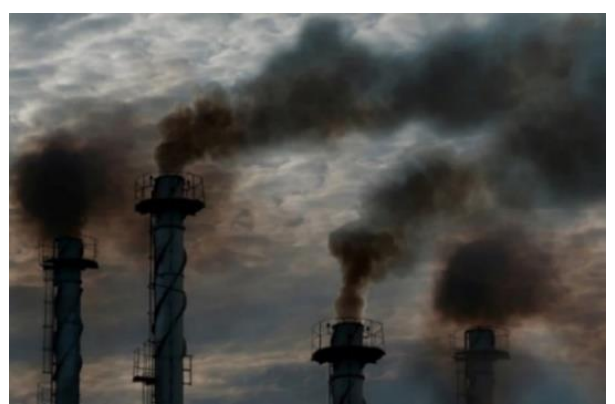

b). Air pollution

Fig. 2. The contamination of the environment by industrial waste from thermal power plants in Vietnam.

TPP "VungAng" produces about 3000 tons of ash and slag waste daily. In addition, anenormous number of gaseous substances and solid particles formed as a result of solid fuel combustion enter the atmosphere through the smokestacks of this power plants [11].

The recycling of waste from industry and agriculture as mineral additives for modern concrete not only saves capital investments but also reduces production cost both in construction material producing and in industries that have so-called "by-products". It contributes to create a non-waste production cycle in the future.

The objective of this study are mathematical modeling the effect of amounts of rice husk ash and fly ash from TPP "VungAng" on the compressive strength of high performance concrete in the form of second-order regression equations. After that, the images of the surface expression and the corresponding contours of the objective function of the regression equation are received.

\section{Materials and Mixture Proportioning}

\subsection{Cement}

Portland Cement (PC) type CEM II 42.5N manufactured at "Nghi Son" factory (Vietnam), specific weight of $3.12 \mathrm{~g} / \mathrm{cm}^{3}$, surface area of $3635 \mathrm{~cm}^{2} / \mathrm{g}$. The results of chemical analysis and mineralogical composition of cement are presented in Table 1 and Table 2.

Table 1. Chemical composition of cement "Nghi Son".

\begin{tabular}{|r|r|r|r|r|r|r|}
\hline \multicolumn{7}{|c|}{ Oxide composition(\%) } \\
\hline $\mathrm{CaO}$ & $\mathrm{SiO}_{2}$ & $\mathrm{~A}_{2} \mathrm{O}_{3}$ & $\mathrm{Fe}_{2} \mathrm{O}_{3}$ & $\mathrm{MgO}$ & $\mathrm{SO}_{3}$ & LOI $^{*}$ \\
\hline 62.23 & 22.27 & 5.37 & 4.12 & 2.4 & 2.626 & 0.984 \\
\hline
\end{tabular}

Note: LOI - loss on ignition. 
Table 2. Mineralogical Composition of cement "Nghi Son".

\begin{tabular}{|c|c|c|c|c|}
\hline \multicolumn{5}{|c|}{ Mineral composition (\%) } \\
\hline $\mathrm{C}_{3} \mathrm{~S}$ & $\mathrm{C}_{2} \mathrm{~S}$ & $\mathrm{C}_{3} \mathrm{~A}$ & $\mathrm{C}_{4} \mathrm{AF}$ & Other \\
\hline 56.3 & 23.4 & 4.7 & 12.4 & 3.2 \\
\hline
\end{tabular}

\subsection{Aggregates}

Quartz sand (QS) originally from the golden sand of "Lo River" (Vietnam), $\mathrm{M}_{\mathrm{K}}=2.85$, specific weight of $2.65 \mathrm{~g} / \mathrm{cm}^{3}$ and the volume of compacted state is $1540 \mathrm{~kg} / \mathrm{m}^{3}$.

Crushed limestone (CL) produced from the quarry "KienKhe" (Vietnam) with the size of $5-10 \mathrm{~mm}$, specific weight of $2.61 \mathrm{~g} / \mathrm{cm}^{3}$ and volume of the compacted state is $1620 \mathrm{~kg} / \mathrm{m}^{3}$.

\subsection{Chemical admixture}

Superplasticizer ACE 388 (A388) "Sure Tec" BASF (Germany). It is a new generation chemical additives based on polycarboxylate ethers with specific weight of $1.1 \mathrm{~g} / \mathrm{cm}^{3}$ at 20 $\pm 5^{\circ} \mathrm{C}$.

\subsection{Mineral additives}

Fly Ash (FA) TPP "VungAng" (Vietnam) Class C and rice husk ash (RHA) with specific weight of 2.22 and $2.15 \mathrm{~g} / \mathrm{cm}^{3}$, the volume of natural porous state are 765 and $572 \mathrm{~kg} / \mathrm{m}^{3}$ and the water needs are 104.1 and $100.7 \%$ respectively. The chemical composition of the FA and RHA are shown in Table 3.

Table 3. Chemical compositions of RHA and FA TPP "VungAng"

\begin{tabular}{|c|c|c|c|c|c|c|c|c|c|c|c|}
\hline \multirow{2}{*}{$\begin{array}{c}\text { Mineral } \\
\text { additives }\end{array}$} & \multicolumn{10}{|c|}{ Average chemical composition(\%) } \\
\cline { 2 - 12 } & $\mathrm{SiO}_{2}$ & $\mathrm{Al}_{2} \mathrm{O}_{3}$ & $\mathrm{Fe}_{2} \mathrm{O}_{3}$ & $\mathrm{SO}_{3}$ & $\mathrm{~K}_{2} \mathrm{O}$ & $\mathrm{Na}_{2} \mathrm{O}$ & $\mathrm{MgO}$ & $\mathrm{CaO}$ & $\mathrm{TiO}_{2}$ & $\mathrm{P}_{2} \mathrm{O}_{5}$ & $\mathrm{LOI}$ \\
\hline RHA & 88.2 & 1.25 & 1.75 & 0.5 & 1.14 & 2.67 & 0.8 & 0.52 & 0.15 & 0.25 & 2.77 \\
\hline $\begin{array}{c}\text { FA TPP } \\
\text { "VungAng" }\end{array}$ & 54.62 & 25.17 & 7.11 & 0.25 & 1.28 & 0.2 & 1.57 & 1.45 & 1.83 & 1.63 & 2.04 \\
\hline
\end{tabular}

Grain compositions of RHA and FA are determined by Laser method, presented in Table 4.

Table 4. The grain of RHA and FA TЭC "VungAng".

\begin{tabular}{|c|c|c|c|c|c|c|}
\hline \multirow{4}{*}{ 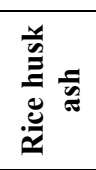 } & \multirow{2}{*}{$\%$ grain sizes less than $\mathrm{D}(\mu \mathrm{m})$} & 10 & 25 & 50 & 75 & 90 \\
\hline & & 1.827 & 3.402 & 7.311 & 24.14 & 63.32 \\
\hline & Specific surface area $(\mu \mathrm{m})$ & \multicolumn{5}{|c|}{8.415} \\
\hline & Specific surface area $\left(\mathrm{m}^{2} / \mathrm{g}\right)$ & \multicolumn{5}{|c|}{11.350} \\
\hline \multirow{4}{*}{$\begin{array}{l}\frac{5}{n} \\
\frac{2}{2} \\
\frac{2}{x}\end{array}$} & \multirow{2}{*}{$\%$ grain sizes less than $\mathrm{D}(\mu \mathrm{m})$} & 10 & 25 & 50 & 75 & 90 \\
\hline & & 1.025 & 2.812 & 3.873 & 27.65 & 64.64 \\
\hline & Specific surface area $(\mu \mathrm{m})$ & \multicolumn{5}{|c|}{2.588} \\
\hline & Specific surface area $\left(\mathrm{m}^{2} / \mathrm{g}\right)$ & \multicolumn{5}{|c|}{14.455} \\
\hline
\end{tabular}

\subsection{Methods}

Method of calculation preliminary compositions of concrete mixture is applied in accordance with ACI 211.4R-93 (American). According to [12], the flowability of concrete mixture is determined by the slump flow of Abrams' cone with dimensions of 100x200x300 mm. The 
compressive strength of concrete is determined by a 100x100x100 mm cube pattern by Russian standard GOST 10180-2012. These cube samples are demolded after 24 hours later casting and placed in a $20^{\circ} \mathrm{C}$ water curing tank until the experiments. The compressive strength HPC is measured at the ages of 3, 7 and 28 days [13].

\subsection{Mathematical modeling method}

In this paper, the achieved second-order regression equations of the objective function is the compressive strength of HPC by using method of the Central composite rotatable design (CCRD) for two factors [14]. The method CCRD allows to obtain more accurately mathematical description by increasing the number of experiments at the center and a special value of "star shoulder" $\alpha=\sqrt{2}=1.414$ [26].

The geometric interpretation of the CCRD for the two factors is a square, is shown in

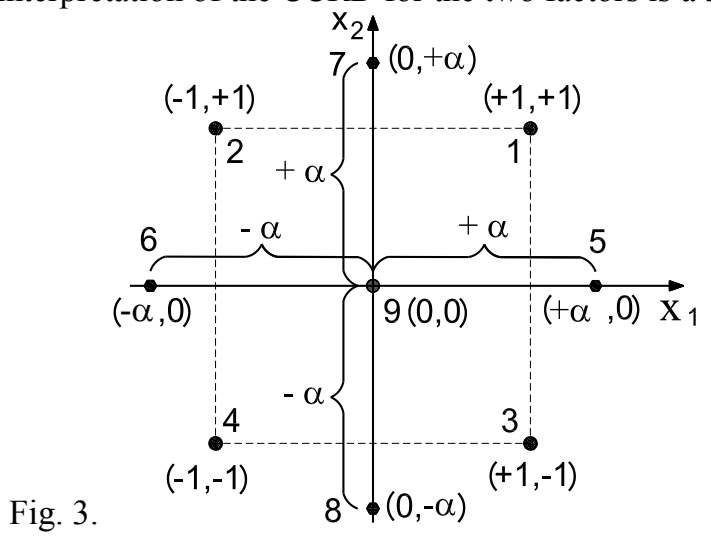

Fig. 3. Geometric interpretation of the CCRD for two factors.

\section{Results and Discussion}

Development of high performance concrete must possess:

- the effect of the fresh concrete with the workability is determined by the slump-flow $600 \div 700 \mathrm{~mm}$;

- compressive strength at the age of 28 days is higher than $70 \mathrm{MPa}$.

- durability and corrosion resistance in corrosive environment.

- reduce cement consumption.

The preliminary composition of the concrete mixture was calculated according to the standard ACI 211.4R-93 [15]. The properties of the fresh concrete as well as the compressive strength of concrete areachievedand presented in Table 3.

Table 3. Preliminary compositions, properties of fresh concretes and high performance concrete.

\begin{tabular}{|c|c|c|c|c|c|c|c|c|c|c|}
\hline \multicolumn{9}{|c|}{ Compositions of concrete mixture, $\mathbf{k g} / \mathbf{m}^{3}$} & \multicolumn{3}{|c|}{ Properties of fresh concretes } & Compressive \\
\hline PC & RHA & FA & QS & CL & W & A388 & $\begin{array}{c}\text { Average } \\
\text { density } \\
\left(\mathrm{kg} / \mathrm{m}^{3}\right)\end{array}$ & $\begin{array}{c}\text { W } \\
\text { BID }\end{array}$ & $\begin{array}{c}\text { Slump } \\
\text { flow } \\
(\mathrm{mm})\end{array}$ & $\begin{array}{c}\text { congth at 28 } \\
\text { days (MPa) }\end{array}$ \\
\hline 392 & 59 & 118 & 533 & 1053 & 159 & 5.7 & 2319.7 & 0.28 & 620 & 72 \\
\hline
\end{tabular}

The water/binding ratio is constant and equal to $\frac{\mathrm{W}}{\mathrm{BID}}=0.28$. The amount of superplasticizer A388 is $1 \%$ by the mass of the binder. The amounts of RHA and FA in the 
composite binder ( $\mathrm{PC}+\mathrm{RHA}+\mathrm{FA})$ are chosen, respectively, in the range from $8 \%$ to $22 \%$ and from $20 \%$ to $40 \%$ by the mass of Portland cement. While the contents of QS is $533 \mathrm{~kg}$ and $\mathrm{CL}$ is $1053 \mathrm{~kg}$.

Definition of objective functions for the description of empirical models:

$\mathrm{Yi}(\mathrm{i}=3,7$ and 28$)$ - the compressive strength of the samples HPC $\left(\mathrm{R}_{\mathrm{HPC}}, \mathrm{MPa}\right)$ at the ages of 3, 7 and 28 days are considered as an objective functions of the experimental model.

Input factors and their limitationare sorted as below:

- $\mathrm{x}_{1}$ - the amount of RHA, is in the range from 0.08 to 0.22 by mass PC;

- $\mathrm{x}_{2}$ - the amount of FA, is in the range from 0.2 to 0.4 by mass PC.

The input factors and intervals of their variation are shown in Table 4.

Table 4. Levels and intervals of varying factors of the CCRD.

\begin{tabular}{|c|c|c|c|c|c|c|c|}
\hline \multicolumn{2}{|c|}{ Factors } & \multicolumn{5}{|c|}{ Levels varying factors } & \multirow{2}{*}{$\begin{array}{c}\text { Intervals varying } \\
\text { factors }\end{array}$} \\
\hline Parameter & Description & 1.414 & -1 & 0 & +1 & +1.414 & \\
\hline Amount of RH & $\mathrm{x}$ & 0 & 0 & 0 . & 年 & 0 & 0.0083 \\
\hline Amount of FA & $\mathrm{x}_{2}$ & 0.2067 & 0.215 & 0.3 & 0.385 & 0.3933 & 0.085 and 0.0083 \\
\hline
\end{tabular}

The number experiments of CCRD for the two factors is indicatedby formula (1):

$$
N=2^{\mathrm{k}}+2 \times \mathrm{k}+\mathrm{m}
$$

where: $\mathrm{k}$ - thenumber of factors, $\mathrm{k}=2$;

$\mathrm{m}-$ the number of repeating the experiments at the center, $\mathrm{m}=5$ according to [28].

Consequently: $N=2^{2}+2 \times 2+5=13$.

Compositions of high performance concrete, calculated by the method of central composite rotatable design for two factors, are displayed in Table 5. The valuesof compressive strength HPC at the ages of 3, 7 and 28 days of normal hardening are presented in Tables $6-8$.

Table 5. Matrix of the CCRD for two factors and compositions of concrete mixtures.

\begin{tabular}{|c|c|c|c|c|c|c|c|c|c|c|c|}
\hline $\begin{array}{c}\text { Trial } \\
\text { No. }\end{array}$ & \begin{tabular}{c} 
Descriptionof code \\
\cline { 2 - 13 }
\end{tabular} & \multicolumn{1}{|c|}{ Parameter } & \multicolumn{6}{c|}{ Compositions of concrete mixtures $\left(\mathbf{k g} / \mathbf{m}^{3}\right)$} \\
\hline 1 & +1 & +1 & 0.22 & 0.385 & 349 & 77 & 134 & 533 & 1053 & 157 & 5.6 \\
\hline 2 & -1 & +1 & 0.08 & 0.385 & 388 & 31 & 149 & 533 & 1053 & 159 & 5.7 \\
\hline 3 & +1 & -1 & 0.22 & 0.215 & 396 & 87 & 85 & 533 & 1053 & 159 & 5.7 \\
\hline 4 & -1 & -1 & 0.08 & 0.215 & 447 & 36 & 96 & 533 & 1053 & 162 & 5.8 \\
\hline 5 & +1.414 & 0 & 0.2283 & 0.3 & 369 & 84 & 111 & 533 & 1053 & 158 & 5.6 \\
\hline 6 & -1.414 & 0 & 0.0717 & 0.3 & 418 & 30 & 125 & 533 & 1053 & 160 & 5.7 \\
\hline 7 & 0 & +1.414 & 0.15 & 0.3933 & 365 & 55 & 144 & 533 & 1053 & 158 & 5.6 \\
\hline 8 & 0 & -1.414 & 0.15 & 0.2067 & 423 & 63 & 87 & 533 & 1053 & 160 & 5.7 \\
\hline 9 & 0 & 0 & 0.15 & 0.3 & 392 & 59 & 118 & 533 & 1053 & 159 & 5.7 \\
\hline 10 & 0 & 0 & 0.15 & 0.3 & 392 & 59 & 118 & 533 & 1053 & 159 & 5.7 \\
\hline 11 & 0 & 0 & 0.15 & 0.3 & 392 & 59 & 118 & 533 & 1053 & 159 & 5.7 \\
\hline 12 & 0 & 0 & 0.15 & 0.3 & 392 & 59 & 118 & 533 & 1053 & 159 & 5.7 \\
\hline 13 & 0 & 0 & 0.15 & 0.3 & 392 & 59 & 118 & 533 & 1053 & 159 & 5.7 \\
\hline
\end{tabular}


Table 6. Compressive strength of HPC at 3 days.

\begin{tabular}{|c|c|c|c|c|c|c|c|c|c|c|c|}
\hline \multirow{2}{*}{$\begin{array}{c}\text { Trial } \\
\text { No. }\end{array}$} & \multirow[b]{2}{*}{ RHA } & \multirow[b]{2}{*}{ FA } & \multicolumn{5}{|c|}{ Description of code } & \multicolumn{2}{|c|}{$\mathbf{Y}_{3}=\mathbf{R}^{3}{ }_{\mathrm{HPC}}(\mathrm{MPa})$} & \multirow[b]{2}{*}{$\left(Y_{3 j}-\hat{Y}_{3 j}\right)$} & \multirow{2}{*}{$\left(Y_{03 j}-\hat{Y}_{03}\right.$} \\
\hline & & & $\mathbf{x}_{1}$ & $\mathbf{x}_{2}$ & $\mathbf{x}_{1}{ }^{2}$ & $\mathbf{x}_{1} \mathbf{x}_{2}$ & $\mathbf{x}_{2}{ }^{2}$ & $\mathbf{Y}_{3 \mathbf{j}}$ & $\hat{Y}_{3 j}$ & & \\
\hline 1 & 0.22 & 0.385 & +1 & +1 & 1 & 1 & 1 & 45.50 & 46.32 & 0.668 & - \\
\hline 2 & 0.08 & 0.385 & -1 & +1 & 1 & -1 & 1 & 48.13 & 52.54 & 19.472 & - \\
\hline 3 & 0.22 & 0.215 & +1 & -1 & 1 & -1 & 1 & 44.21 & 42.90 & 1.711 & - \\
\hline 4 & 0.08 & 0.215 & -1 & -1 & 1 & 1 & 1 & 47.70 & 49.13 & 2.037 & - \\
\hline 5 & 0.2283 & 0.3 & +1.414 & 0 & 2 & 0 & 0 & 43.30 & 44.08 & 0.610 & - \\
\hline 6 & 0.0717 & 0.3 & -1.414 & 0 & 2 & 0 & 0 & 56.62 & 52.86 & 14.148 & - \\
\hline 7 & 0.15 & 0.3933 & 0 & +1.414 & 0 & 0 & 2 & 52.70 & 49.38 & 11.004 & - \\
\hline 8 & 0.15 & 0.2067 & 0 & -1.414 & 0 & 0 & 2 & 44.23 & 44.57 & 0.113 & - \\
\hline 9 & 0.15 & 0.3 & 0 & 0 & 0 & 0 & 0 & 53.26 & 54.95 & 2.843 & 2.843 \\
\hline 10 & 0.15 & 0.3 & 0 & 0 & 0 & 0 & 0 & 55.92 & 54.95 & 0.949 & 0.949 \\
\hline 11 & 0.15 & 0.3 & 0 & 0 & 0 & 0 & 0 & 54.30 & 54.95 & 0.417 & 0.417 \\
\hline 12 & 0.15 & 0.3 & 0 & 0 & 0 & 0 & 0 & 56.10 & 54.95 & 1.332 & 1.332 \\
\hline 13 & 0.15 & 0.3 & 0 & 0 & 0 & 0 & 0 & 55.15 & 54.95 & 0.042 & 0.042 \\
\hline \multicolumn{4}{|c|}{$\sum\left(Y_{3 j}-\hat{Y}_{3 j}\right)^{2}=55.346$} & \multicolumn{2}{|c|}{$\mathrm{S}_{\mathrm{d}^{2}}=6.918$} & \multicolumn{4}{|c|}{$\sum\left(\mathrm{Y}_{03 \mathrm{j}}-\hat{\mathrm{Y}}_{03 \mathrm{j}}\right)^{2}=5.582$} & \multicolumn{2}{|c|}{$\mathrm{S}_{11}^{2}=1.395$} \\
\hline
\end{tabular}

Table 7. Compressive strength of HPC at 7 days.

\begin{tabular}{|c|c|c|c|c|c|c|c|c|c|c|c|}
\hline \multirow{2}{*}{$\begin{array}{c}\text { Tria } \\
\text { I No. }\end{array}$} & \multirow{2}{*}{ RHA } & \multirow{2}{*}{ FA } & \multicolumn{5}{|c|}{ Description of code } & \multicolumn{2}{|c|}{$\mathbf{Y}_{7}=\mathbf{R}^{7}{ }_{\text {HPC }}(\mathbf{M P a})$} & \multirow{2}{*}{$\left(Y_{7 j}-\hat{Y}_{7 j}\right)^{2}$} & \multirow{2}{*}{$\left(Y_{07 j}-\hat{Y}_{07 j}\right.$} \\
\hline & & & $\mathbf{x}_{1}$ & $\mathbf{x}_{2}$ & $\mathbf{x}_{1}{ }^{2}$ & $\mathbf{x}_{1} \mathbf{x}_{2}$ & $\mathbf{x}_{2}{ }^{2}$ & $\mathrm{Y}_{7 \mathrm{j}}$ & $\bar{Y}_{7 j}$ & & \\
\hline 1 & 0.22 & 0.385 & +1 & +1 & 1 & 1 & 1 & 61.35 & 61.43 & 0.006 & - \\
\hline 2 & 0.08 & 0.385 & -1 & +1 & 1 & -1 & 1 & 64.92 & 65.48 & 0.309 & - \\
\hline 3 & 0.22 & 0.215 & +1 & -1 & 1 & -1 & 1 & 60.19 & 58.07 & 4.479 & - \\
\hline 4 & 0.08 & 0.215 & -1 & -1 & 1 & 1 & 1 & 63.54 & 62.12 & 2.019 & - \\
\hline 5 & 0.2283 & 0.3 & +1.414 & 0 & 2 & 0 & 0 & 59.25 & 60.19 & 0.888 & - \\
\hline 6 & 0.0717 & 0.3 & -1.414 & 0 & 2 & 0 & 0 & 65.80 & 65.91 & 0.013 & - \\
\hline 7 & 0.15 & 0.3933 & 0 & +1.414 & 0 & 0 & 2 & 63.82 & 62.87 & 0.901 & - \\
\hline 8 & 0.15 & 0.2067 & 0 & -1.414 & 0 & 0 & 2 & 56.12 & 58.12 & 4.016 & - \\
\hline 9 & 0.15 & 0.3 & 0 & 0 & 0 & 0 & 0 & 64.30 & 65.47 & 1.364 & 1.364 \\
\hline 10 & 0.15 & 0.3 & 0 & 0 & 0 & 0 & 0 & 66.21 & 65.47 & 0.551 & 0.551 \\
\hline 11 & 0.15 & 0.3 & 0 & 0 & 0 & 0 & 0 & 66.30 & 65.47 & 0.692 & 0.692 \\
\hline 12 & 0.15 & 0.3 & 0 & 0 & 0 & 0 & 0 & 65.10 & 65.47 & 0.135 & 0.135 \\
\hline 13 & 0.15 & 0.3 & 0 & 0 & 0 & 0 & 0 & 65.43 & 65.47 & 0.001 & 0.001 \\
\hline \multicolumn{4}{|c|}{$\sum\left(Y_{7 j}-\hat{Y}_{7 j}\right)^{2}=15.375$} & \multicolumn{2}{|c|}{$\mathrm{S}_{\mathrm{d}}^{2}=1.922$} & \multicolumn{4}{|c|}{$\sum\left(Y_{07 \mathrm{j}}-\widehat{Y}_{07 \mathrm{j}}\right)^{2}=2.74$} & \multicolumn{2}{|c|}{$\mathrm{S}_{11^{2}}=0.686$} \\
\hline
\end{tabular}


Table 8. Compressive strength of HPC at 28 days.

\begin{tabular}{|c|c|c|c|c|c|c|c|c|c|c|c|}
\hline \multirow{2}{*}{$\begin{array}{l}\text { Trial } \\
\text { No. }\end{array}$} & \multirow{2}{*}{ RHA } & \multirow{2}{*}{ FA } & \multicolumn{5}{|c|}{ Description of code } & \multicolumn{2}{|c|}{$\begin{array}{c}\mathrm{Y}_{28}=\mathrm{R}^{28} \mathrm{HPC}(\mathrm{MPa} \\
)\end{array}$} & \multirow{2}{*}{$\left(Y_{28 \mathrm{j}}-\hat{Y}_{28 \mathrm{j}}\right)^{2}$} & \multirow{2}{*}{$\left(Y_{028 j}-\hat{Y}_{028 j}\right.$} \\
\hline & & & $\mathrm{x}_{1}$ & $\mathrm{x}_{2}$ & $\mathrm{x}_{1}{ }^{2}$ & $\mathrm{x}_{1} \mathrm{X}_{2}$ & $\mathrm{x}_{2}{ }^{2}$ & $Y_{28 j}$ & $\bar{Y}_{28 j}$ & & \\
\hline 1 & 0.22 & 0.385 & +1 & +1 & 1 & 1 & 1 & 73.35 & 70.32 & 9.193 & - \\
\hline 2 & 0.08 & 0.385 & -1 & +1 & 1 & -1 & 1 & 75.92 & 74.21 & 2.931 & - \\
\hline 3 & 0.22 & 0.215 & +1 & -1 & 1 & -1 & 1 & 69.89 & 68.87 & 1.040 & - \\
\hline 4 & 0.08 & 0.215 & -1 & -1 & 1 & 1 & 1 & 74.24 & 72.76 & 2.190 & - \\
\hline 5 & 0.2283 & 0.3 & +1.414 & 0 & 2 & 0 & 0 & 66.27 & 68.16 & 3.559 & - \\
\hline 6 & 0.0717 & 0.3 & -1.414 & 0 & 2 & 0 & 0 & 72.38 & 73.66 & 1.630 & - \\
\hline 7 & 0.15 & 0.3933 & 0 & +1.414 & 0 & 0 & 2 & 70.82 & 73.20 & 5.641 & - \\
\hline 8 & 0.15 & 0.2067 & 0 & -1.414 & 0 & 0 & 2 & 70.36 & 71.15 & 0.621 & - \\
\hline 9 & 0.15 & 0.3 & 0 & 0 & 0 & 0 & 0 & 74.75 & 76.32 & 2.452 & 2.452 \\
\hline 10 & 0.15 & 0.3 & 0 & 0 & 0 & 0 & 0 & 78.21 & 76.32 & 3.587 & 3.587 \\
\hline 11 & 0.15 & 0.3 & 0 & 0 & 0 & 0 & 0 & 75.12 & 76.32 & 1.430 & 1.430 \\
\hline 12 & 0.15 & 0.3 & 0 & 0 & 0 & 0 & 0 & 76.25 & 76.32 & 0.004 & 0.004 \\
\hline 13 & 0.15 & 0.3 & 0 & 0 & 0 & 0 & 0 & 77.25 & 76.32 & 0.872 & 0.872 \\
\hline \multicolumn{10}{|c|}{$\sum\left(\mathrm{Y}_{28 \mathrm{j}}-\widehat{\mathrm{Y}}_{28 \mathrm{j}}\right)^{2}=35.152 \mathrm{~S}_{\mathrm{d}}^{2}=4.394 \mid \sum\left(\mathrm{Y}_{028 \mathrm{j}}-\widehat{Y}_{028 \mathrm{j}}\right)^{2}=8.3$} & \multicolumn{2}{|c|}{$\mathrm{S}_{11^{2}}=2.087$} \\
\hline
\end{tabular}

Checking the adequacy of the experimental model. According to [27-29],the adequacy of the regression equations is checked by means of the Fisher criterion. The calculated value of which is the following ratio (2):

$$
F_{i}=\frac{S_{d}^{2}}{S_{\|}^{2}}
$$

where: $S^{2}{ }_{11}$ - variance estimates the reproducibility of the experiment, determined by formula (3):

$$
S_{\|}^{2}=\frac{\sum_{j=1}^{m}\left(Y_{o j}-\hat{Y}_{o}\right)^{2}}{m-1}
$$

where: $\mathrm{m}$ - the number of repeated experiments at the center, $\mathrm{m}=5$;

$\mathrm{Y}_{\mathrm{oj}}$ - the obtained value of the $\mathrm{i}$-th experiment at the center;

$\widehat{Y}_{0}$ - the average value of $\mathrm{m}$ of the experiments at the center;

$\mathrm{S}^{2}{ }_{\mathrm{d}}$ - estimation of the dispersion of inadequacy, determined by the formula (4):

where:

$$
S_{d}^{2}=\frac{\sum_{j=1}^{N}\left(Y_{j}-\hat{Y}_{j}\right)^{2}}{N-B}
$$

$\mathrm{B}$-the number of coefficients of the second-order regression equation, which are significant, $\mathrm{B}=5$;

$\mathrm{Y}_{\mathrm{j}}$ - the observed value of the $\mathrm{i}$-th experiment; 
$\widehat{Y}_{j}$-the obtained value of the experimental function in accordance with the $\mathrm{i}$-th experiment;

$F_{\alpha},\left(f_{1}, f_{2}\right)$-the value Fisher criterion with a significant level of $\alpha=0,05$;

where: $f_{1}$ - number of degrees of freedom for residual variance, $f_{1}=N-B=13-5=8$;

$f_{2}$-number of degrees of freedom for estimating the variance of observations, $f_{2}=m-1=5$ $1=4$.

Consequently: $\mathrm{F}_{0,05}(8,4)=6,0410$.

The second-order regression equations (5), (6) and (7), the values of the coefficients, the images of response surface and corresponding contour plot in Figure $4-6$ are obtained by Matlab program.

$$
\begin{gathered}
\mathrm{Y}_{3}=\mathrm{R}_{\mathrm{HPC}}^{3}=54.95-3.12 \mathrm{x}_{1}+1.712 \mathrm{x}_{2}-3.201 \mathrm{x}_{1}^{2}-3.948 \mathrm{x}_{2}^{2}+0.215 \mathrm{x}_{1} \mathrm{x}_{2}(\mathrm{MPa}) \\
\mathrm{F}_{3}=\frac{\mathrm{S}_{\mathrm{d}}^{2}}{\mathrm{~S}_{\|}^{2}}=\frac{6.918}{1.395}=4.9576 .
\end{gathered}
$$

As $F_{3}=4.9576<F_{0,05}(8,4)=6.0410$, the experimental model described by equation (5) is adequate.
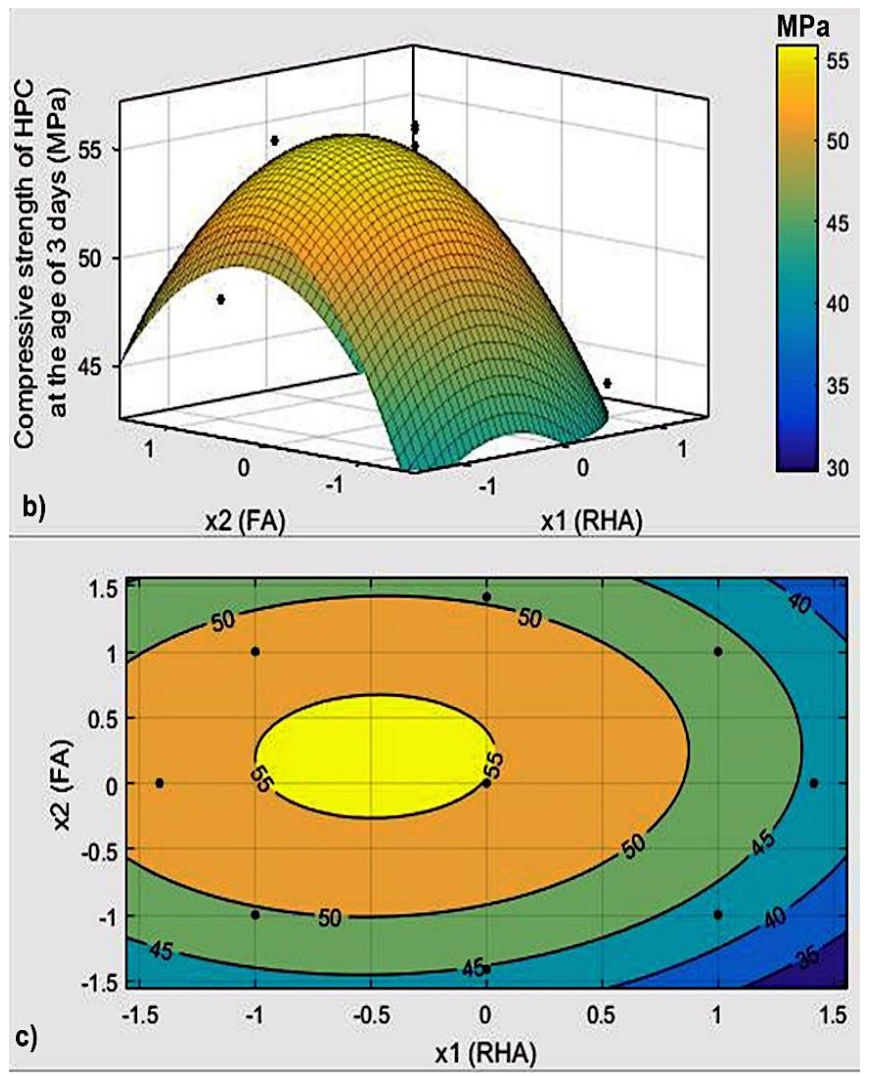

Fig. 4. The coefficients a), response surface b) and contour plot c) of the second-order regression equation (5) for compressive strength of HPC at the age of 3 days.

$$
\mathrm{Y}_{7}=\mathrm{R}_{\mathrm{HPC}}^{7}=65.47-2.023 \mathrm{x}_{1}+1.679 \mathrm{x}_{2}-1.158 \mathrm{x}_{1}^{2}-2.436 \mathrm{x}_{2}^{2}-0.055 \mathrm{x}_{1} \mathrm{x}_{2}(\mathrm{MPa})
$$


The program Maple 13 provides $\mathrm{MaxY}_{3}{ }^{\mathrm{opt}}=55.874$ at x $_{1}{ }^{\text {opt }}=-0.4805$ and $\mathrm{x}_{2}{ }^{\text {opt }}=0.2037$. Then, $\operatorname{Max} \mathrm{R}^{3}{ }_{\mathrm{HPC}}=55.874 \mathrm{MPa}$ at $\mathrm{RHA}=0.1164$ and $\mathrm{FA}=0.3173$ by mass $\mathrm{PC}$, represented at point A in Fig. 7.
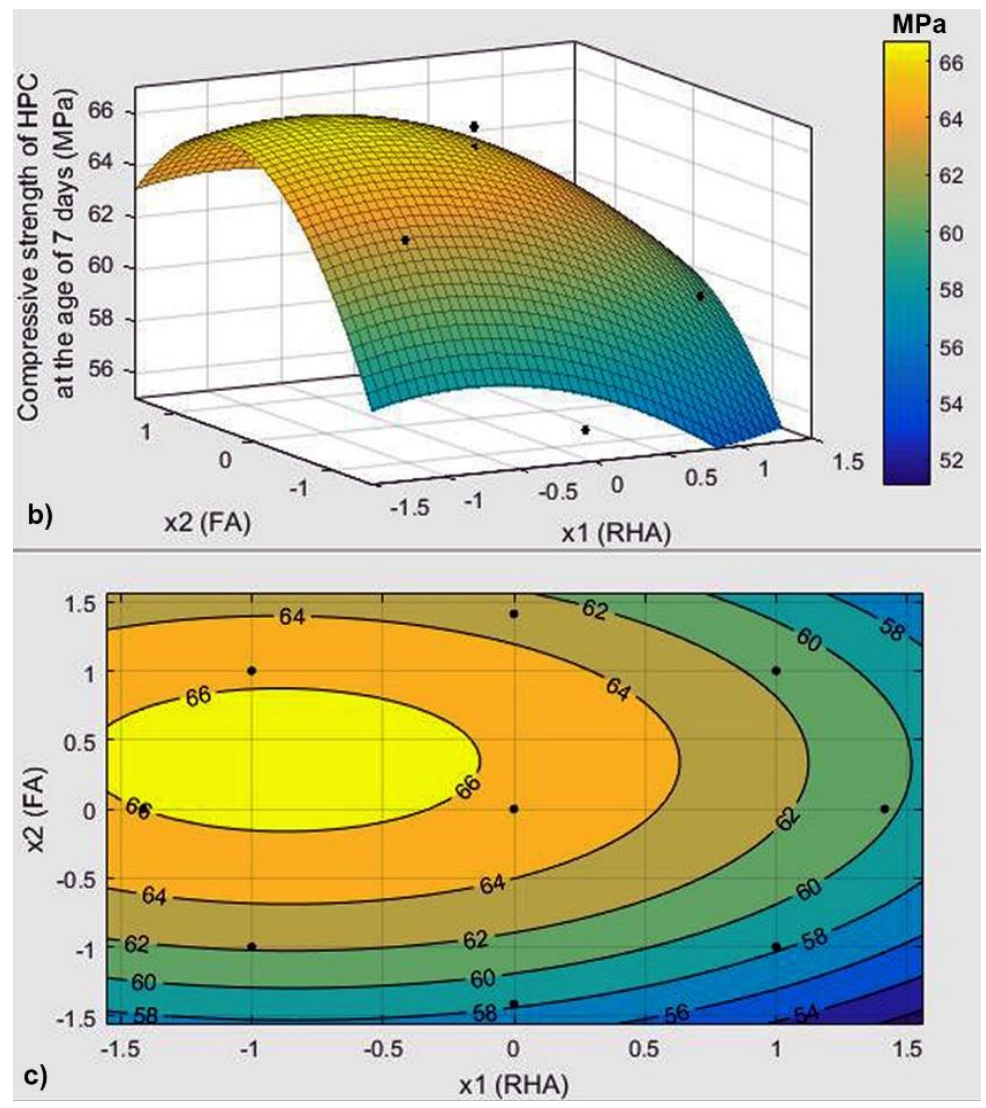

Fig. 5. The coefficients a), response surface b) and contour plot c) of the second-order regression equation (6) for compressive strength of HPC at 7 days.

$$
\mathrm{Y}_{28}=\mathrm{R}^{28}{ }_{\mathrm{HPC}}=76.32-1.945 \mathrm{x}_{1}+0.7239 \mathrm{x}_{2}-2.647 \mathrm{x}_{1}{ }^{2}-2.015 \mathrm{x}_{2}{ }^{2}+0.445 \mathrm{x}_{1} \mathrm{x}_{2}(\mathrm{MPa})
$$

The program Maple 13 shows MaxY ${ }_{7}{ }^{\text {opt }}=66.6597$ at $\mathrm{x}_{1}{ }^{\mathrm{opt}}=-0.8819$ and $\mathrm{x}_{2}{ }^{\mathrm{opt}}=0.3546$. Then, Max $\mathrm{R}^{7}{ }_{\mathrm{HPC}}=66.6597 \mathrm{MPa}$ at $\mathrm{RHA}=0.0883$ and $\mathrm{FA}=0.3301$ by mass $\mathrm{PC}$, represented at point $\mathrm{B}$ in Figure 7. 

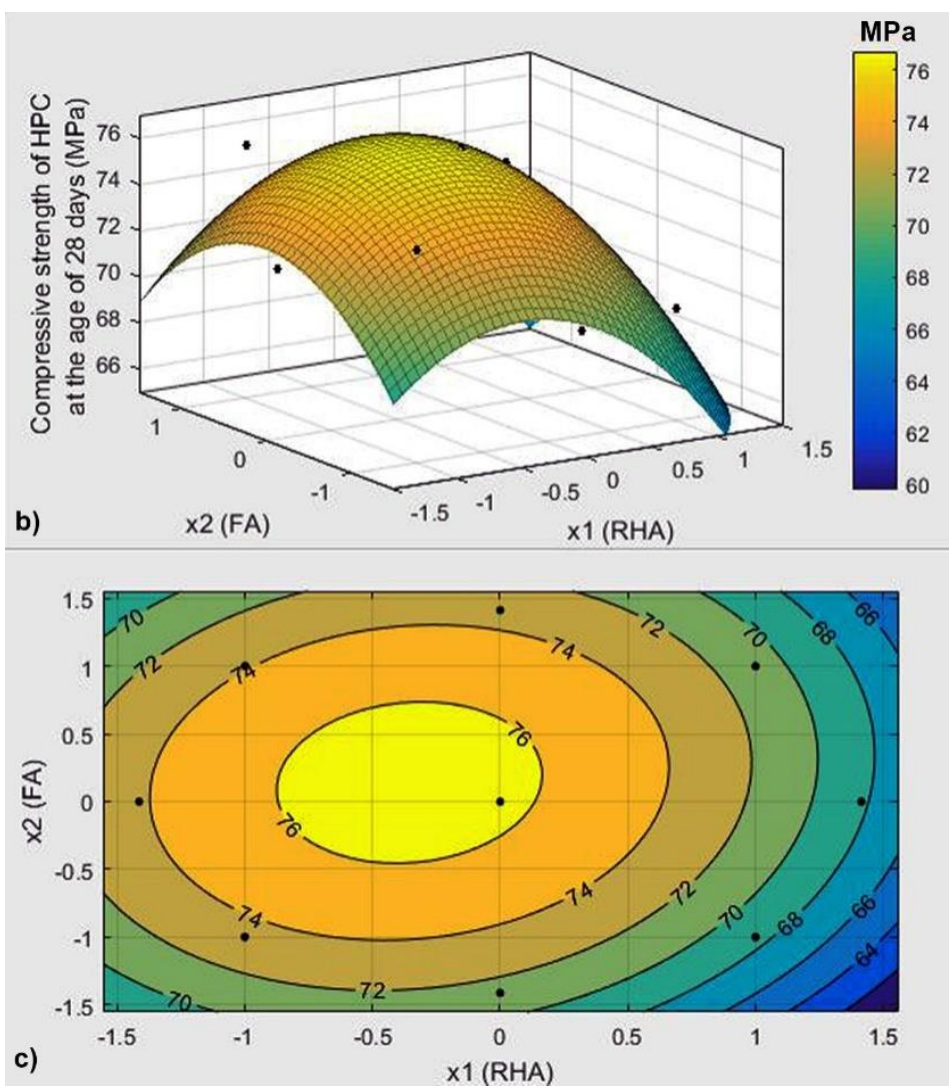

Fig. 6. The coefficients a), response surface b) and contour plot c) of the second order regression equation (7) for compressive strength of HPC at 28 days.

The program Maple 13 provides Max $\mathrm{Y}_{28}{ }^{\mathrm{opt}}=76.716$ at $\mathrm{x}_{1}{ }^{\mathrm{opt}}=-0.3554$ and $\mathrm{x}_{2}{ }^{\mathrm{opt}}=0.1395$. Then, $\operatorname{Max} \mathrm{R}^{28}{ }_{\mathrm{HPC}}=76.716 \mathrm{MPa}$ at $\mathrm{RHA}=0.1251$ and $\mathrm{FA}=0.3119$ by mass Portland cement, represented at point $\mathrm{C}$ in Fig. 7.

Figure 7 presents the curve of dependence of the compressive strength HPC on the amount of RHA and FA at the ages of 3, 7 and 28 days. This curve passes through points A, B and $\mathrm{C}$, which are points of the optimum compressive strength of HPC at the age of 3, 7 and 28 days. 


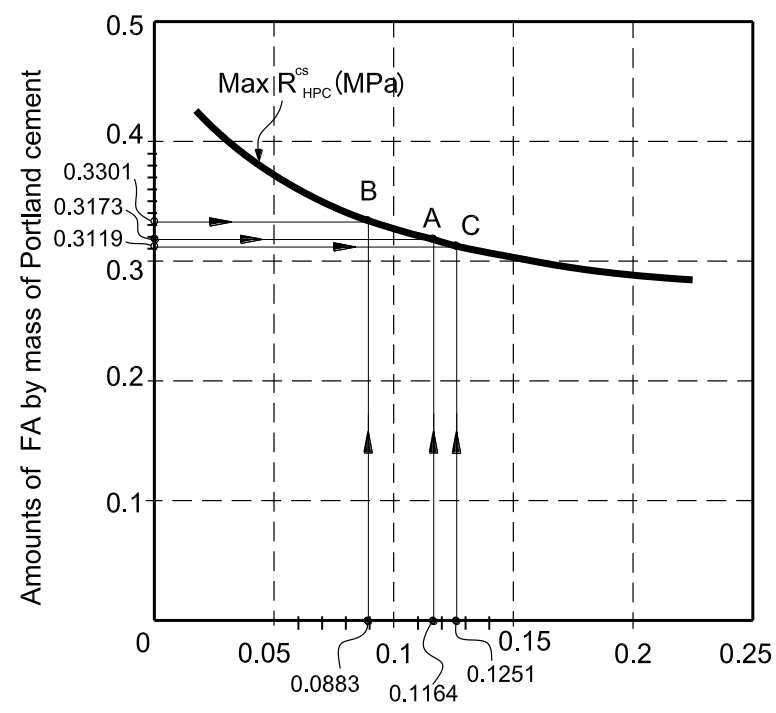

Amounts of RHA by mass of Portland cement

Fig. 7. Compressive strengthof HPC of amountsRHAand FA: A- optimum point of compressive strength of HPC at the age of 3 days; B - optimum point of compressive strength of HPC at the age of 7 days; $\mathrm{C}$ - optimum point of compressive strength of HPC at the age of 28 days.

Based on the data in Table. 6 - 8 and Figure $4-6$, the usage of complex organic mineral modifiers, which contains RHA, FA and superplasticizer ACE 388 in an amount of $1 \%$ of the mass of the binder is gradually effective. Furthermore, the speed of concrete hardening is comparativelyhigh at the age of 3 days. It reaches $62.03 \%$ to $78.23 \%$ of its 28 day compressive strength (in Table 6 and Table 8).

\section{Conclusions}

1. RHA in the North of Vietnam and FA TPP "VungAng" have high pozzolanicactivity. The average content of amorphous silicon dioxide of $88.2 \%$ and $54.62 \%$, respectively, are characterized by a low content of harmful impurities (unburned carbon, $\mathrm{SO}_{3}$, sulfur, $\mathrm{P}_{2} \mathrm{O}_{5}$, mineral oils). Therefore, they can be considered as finely dispersed active mineral admixtures for concrete and mortar [16].

2. Using central composite rotatable design combination with Matlab program obtainsthe second-order regression equations (5), (6) and (7), as well as the images of response surface and corresponding contour plot of the objective function for these regression equations, are shown in Fig. 4 - 6. Theseequations adequately describe the dependence of the compressive strength HPC at the ages of 3, 7 and 28 days by the factors $\mathrm{x}_{1}$ (amount of RHA) and $\mathrm{x}_{2}$ (amount of FA).

3. The Maple 13 program determines the maximum value of the objective functioncompressive strength HPC at the age of 28 days in the second-order regression equation (7), is $\mathrm{MaxR}^{28}{ }_{\mathrm{HPC}}=76.716 \mathrm{MPa}$ at $\mathrm{RHA}=0.1251$ and $\mathrm{FA}=0.3119$ by mass of Portland cement.

\section{References}

1. E.B. Entin, L.S. Nefedova, N.V. Strzhalkovskaya, Cem. and its appl., 2 (2012)

2. N.I. Vatin, D.V. Petrosov, A.I. Kalachev, P. Lakhtinen, Mag. of Civ. Eng., 4 (2011)

3. D.F. Houston, American Association of Cereal Chemists, St. Paul, Minnesota (1972) 
4. S.P. Shah, S.H. Ahmad, High performance concrete: Properties and applications. McGraw-Hill, Inc. (1994)

5. A.V. Vurasko, B.N. Driker, Ye.A Mozyreva, L.A. Zemnukhova, A.R. Galimova, N.N. Gulemina, Chem. of veg. raw mat., 4 (2006)

6. Ch.-L. Hwang, Tr.-Ph. Huynh, Constr. and Build. Mat., 101, 1 (2015)

7. Zemnukhova, G.A. Fedorishcheva, A.G. Yegorov, V.I. Sergiyenko, Journ. of Appl. Chem, 2, 78 (2005).

8. N. Van Toan, J. of Constr. Sc. and Techn. 3, 4 (2013)

9. P.K. Mehta, V.M. Malhotra, Adv. in Concr. Techn. (1994)

10. B. Danh Dai. International Scientific Conference "Some new achievements in modern building materials research" (2006)

11. Bl. Sk. Thomas, Ren. and Sust. En. Rev., 82, 3 (2018)

12. H Th. Le, H.-M. Ludwig, Mat. \& Des., 89 (2016)

13. H. Chao-Lung, B. Le Anh-Tuan, Ch. Chun-Tsu, Constr. and Build. Mat., 25, 9 (2011)

14. M. Tuyen Nguyen. Planning of the experiment. Publisher of Science and Technology. Publishing of Science and Technology (2007)

15. ACI 211.4R-93. Guide for selecting proportions for High-Strength Concrete with Portland Cement and Fly Ash (2010)

16. K.-B. Park, S.-J. Kwon, X.-Y. Wang, Constr. and Build. Mat., 105 (2016) 